\title{
Investigation of Activation Kinetics in Geopolymer Paste using Quasielastic Neutron Scattering
}

\author{
Kunal Kupwade-Patil ${ }^{1, *}$, Souleymane O. Diallo², Dewan Zayid Hossain ${ }^{1}$, Md. Rashedul Islam ${ }^{1}$, \\ Erez N. Allouche ${ }^{1}$ \\ ${ }^{1}$ Alternative Cementitious Binders Laboratory (ACBL), Department of Civil Engineering, Louisiana Tech \\ University, Ruston, LA-71272, USA \\ ${ }^{2}$ Chemical and Engineering Materials Division, Oak Ridge National Laboratory, \\ Oak Ridge, TN-3783, USA \\ "Current address: Department of Civil and Environmental Engineering, \\ Massachusetts Institute of Technology, Cambridge, MA-02139 \\ Corresponding Author: kunalk@mit.edu
}

\begin{abstract}
Quasielastic neutron scattering (QENS) has been used to investigate the binding process of water molecules in pastes of calcium geopolymer prepared with low and high calcium fly ash contents, and at two different $\mathrm{NaOH}$ molarities, 10 and $14 \mathrm{M}$. The in-situ measurements were carried at ambient and elevated curing temperatures $\left(60^{\circ} \mathrm{C}\right)$. By carefully monitoring the time evolution of the elastic peak intensity, we infer a gelation process, followed by polymerization and a hardening in the high calcium geopolymer paste at $60^{\circ} \mathrm{C}$, in agreement with previously proposed geopolymerization model. This behavior was neither observed at ambient temperature in both low and high calcium geopolymer cement paste, within the precision of the neutron instrument. Our study clearly shows that a minimal amount of heat is necessary to form gelation and polymerization during the activation process. The activation of geopolymer paste with high $\mathrm{NaOH}$ molarity involves more chemically bound water molecules than that at lower activator concentration. This works shows that the QENS technique can be effectively used to characterize the alkali-activation kinetics in certain geopolymer pastes, and that temperature and molarity of the activator play a vital role in controlling the gel mechanism.
\end{abstract}

Key Words: Fly Ash; Quasielastic Neutron Scattering (QENS); Geopolymer; Characterization; Gelation; Dissolution 


\section{Introduction}

Geopolymer concrete or alkali activated binder is an emerging technology, which has exhibited a wide range of advantages such as high corrosion and temperature resistance, reduced $\mathrm{CO}_{2}$ emission construction material, a minimum energy-consuming binder and also negligible carbon foot print [1,2].

41 Duxson et al. [3-5] introduced the geopolymer reaction process, starting with the dissolution, specific 42 equilibrium, gelation, reorganization and finally leading to polymerization and hardening. The current 43 study investigates the geopolymerization process of fly ash based alkali-activated paste using quasielastic 44 neutron scattering (QENS), a powerful probe for studying dynamical processes in hydrogenous 45 compounds [6].

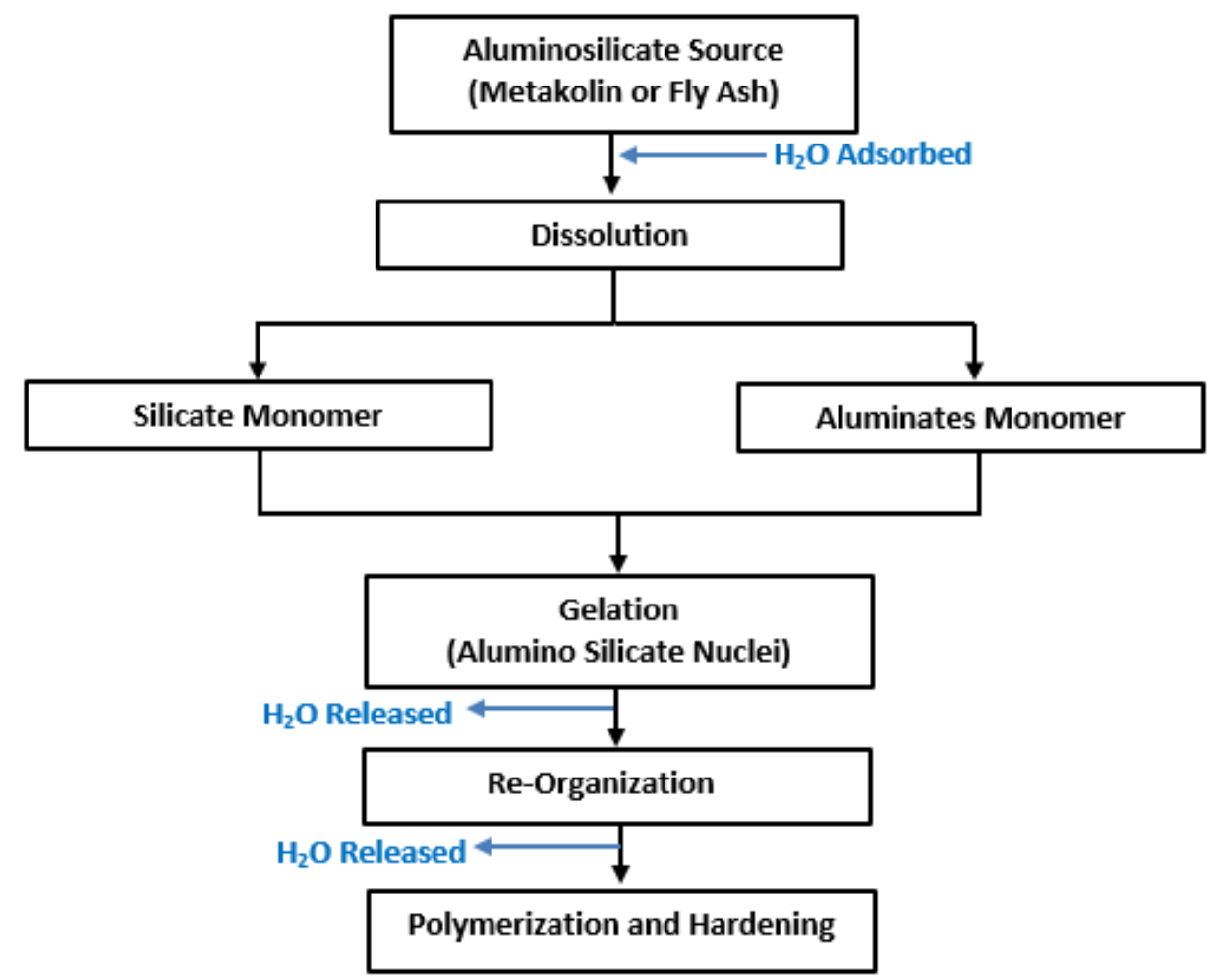

Fig 1. Conceptual geopolymerization model from Duxson et al. (2007). Developed from the concepts from reference $[3,7]$

The geopolymer mechanism introduced in the Figure 1 exhibits a transitional change from a solid alumino silicate source such as fly ash, metakaolin and clay into alkali activated alumino silicate. In the initial stage the solid particles from the source material comes in contact with the alkali solution. This 
causes an amorphous component of these particles to dissolve, releasing aluminate and silicates [8].

55 Dissolution occurs rapidly in amorphous alumina silicates such as fly ash or metakaolin at high $\mathrm{pH}$

56 leading to a supersaturated alumina silicate solution [9]. Upon dissolution, initiation of a complex

57 mixture of aluminosilicate species develops with the ongoing gel rearrangement and crystallization

58 process. In high alkaline solution this leads to gelation during which water that was initially adsorbed

59 during the dissolution stage is released. Details regarding each phase evolution could be found in

60 references $[1,3,10,11]$. This mechanism is validated and well-studied for geopolymers formed with low

61 calcium fly ashes or metakaolin [11]. The understanding of the reaction pathways involving high calcium

62 based precursors is not complete, since the initial model was based fundamentally on the formation of Si-

$63 \mathrm{O}-(\mathrm{Si}, \mathrm{Al})$ bonds [12]. The current study focuses on analyzing this mechanism based on high calcium

64 geopolymers and formation of geopolymeric gels during this dynamic process. Neutron scattering is one

65 of the preferred techniques which can be used to study the dissolution phase of the mechanism [13]. The

66 current work is one of the preliminary studies conducted using in-situ QENS studies on fly ash based

67 geopolymer pastes.

68

69 In the past, several studies have used QENS to understand the metamorphosis of multiphase mechanisms

70 which evolve during the hydration process incorporating alumino silicate source such as fly ash or

71 ground granulated blast furnace slag into Ordinary Portland Cement (OPC) [14-22]. Most studies in the

72 past have dealt with hydration process of OPC incorporating admixtures using QENS technique, while the

73 current study is the first kind where QENS technique is used for examining the alkali activation process in

74 geopolymers. QENS helps in tracking the motion of hydrogen and states of water in the mixture revealing

75 the time-evolution mechanism during the hydration process. During the hydration process the bonding

76 states of water can be distinguished as free, constrained and chemically bound water [14]. Because the

77 neutron signal is largely dominated by hydrogen, the observed immobile molecules are mostly

78 representative of the chemically bound water[23].

79 
The bulk water present in cement matrix is associated to free water, the restricted water is attributed to

81 constrained water where the mobility of water is limited, since it is present inside the gel pores.

82 Chemically bound water is related to the structural water present inside the calcium silicate hydrates

83 which is a hydration product of OPC based system. Details regarding the calculation of the free and

84 constrained water could be found elsewhere [13, 14, 24]. Understanding the alkali activation process has

85 been a great challenge for cement chemists and material scientists [11]. QENS assists in determining the

86 chemically bound water, a parameter that is, in studying the microstructural evolution during the

87 hydration, and that can be related to the nucleation and growth of synthetic gels such as calcium-silicate-

88 hydrate(C-S-H), calcium aluminosilicate hydrate (C-A-S-H) and sodium alumino silicate hydrate (N-A-S-

89 H) $[25,26]$.

90

$91 \mathrm{C}-\mathrm{S}-\mathrm{H}$ is the binding agent in Portland cements; while potassium-alumino-silicate-hydrate (K-A-S-H) or

$92 \mathrm{~N}-\mathrm{A}-\mathrm{S}-\mathrm{H}$ gel is considered as a predominant glue in geopolymers depending on the type of activator

93 (potassium hydroxide or sodium hydroxide) used during the alkali activation process[4, 12, 27]. C-A-S-H

94 gels are formed upon alkali activation of Blast Furnace Slag (BFS) and the formation of the structure is

95 governed by the type of activator used for alkali activation. Sodium hydroxide activated BFS exhibits

96 ordered and layered structures of C-A-S-H gel than silicate activated binders [28, 29]. A density

97 functional theory (DFT) based atomistic model of N-A-S-H gel was examined at elevated

98 temperatures[30]. As seen in C-S-H gels, the $\mathrm{Si}: \mathrm{Al}$ and $\mathrm{Ca}: \mathrm{Mg}$ ratio plays a vital role in governing the

99 initial activation process and therefore the chemistry of the precursor materials (fly ash or Metakaolin)

100 and activators need to be selected carefully before the geopolymerization process. Although, several

101 studies have been published on N-A-S-H gels, but the role of water during activation and

102 geopolymerization process is an active area of research. The current study provides an insight into the

103 activation kinetics and the movement of water during the course of alkali activation. The current study

104 reports the first application of QENS to study alkali activated materials using low and high calcium 
content fly ashes. This technique was used to study the diffusional water dynamics and water bonding during initial period ( 10 hours) of the activation process.

Recent studies conducted by Suraneni et al. 2014 [31] show that set times of geopolymer cements can significantly vary as compared to Portland cements. The variation in setting times is influenced by calcium oxide content, LOI and particle size distribution of the precursor material (fly ash) [32]. Although, measurement of setting time via Vicat needle test as per ASTM C191 has been used for

112 measuring setting times of Portland cements, it does not provide an insight into the chemical reactions 113 taking place during hydration [33]. A relatively new technique known as Ultrasonic Wave Reflection 114 (UWR) could compliment the setting behavior obtained via QENS technique [34]. In UWR, a buffer material is used where an acoustic impedance is detected and the intensity of the buffer/sample is observed as a function of time. However, using UWR the shear waves can propagate in solids and not 117 fluids, thus the water dynamics of cement paste cannot be accurately measured using UWR technique. QENS, can successfully track the motion of water during hydration providing an insight into the rotational and translation motion of the free water during the course of hydration.

\section{Experimental Procedure}

123 Geopolymer paste was prepared using high and low calcium fly ash and was alkali activated by sodium 124 silicate and sodium hydroxide solution, just before the neutron measurements. The chemical composition 125 of the fly ashes is shown in Table 1. Chemical analysis of the fly ash samples was performed via Xray fluorescence (XRF) following ASTM standard D 4326 using a Thermo Scientific ARL

127 Quant'x Energy-Dispersive XRF Spectrometer [35]. DH and MO were designated as low $(\mathrm{CaO}=$ $1285 \%)$ and high $(\mathrm{CaO}=12.93 \%)$ calcium fly ashes respectively. An activator/binder ratio of 0.6 was 129 maintained throughout the experiment. The activator solution consisting of sodium hydroxide: sodium 130 silicate was maintained 1:1, while the fly ash was the binder. A 10 and $14 \mathrm{M}$ sodium hydroxide and 

used in the preparation of the geopolymer paste. The geopolymer paste was prepared by addition of the sodium silicate to the fly ash and mixing it for 1 minute. The mixture was then alkali activated by adding the sodium hydroxide. The mixture was uniformly stirred for 1 minute and a thin paste was applied on the glass slide, as shown in Figure 2. The geopolymer paste was sandwiched between two quartz slides. An aluminum foil was wrapped inside the sample holder and the geopolymer paste was placed inside the specimen holder. The specimen was then placed in the high resolution backscattering spectrometer (BASIS) at the spallation neutron source (SNS) at the Oak Ridge National Laboratory (ORNL).
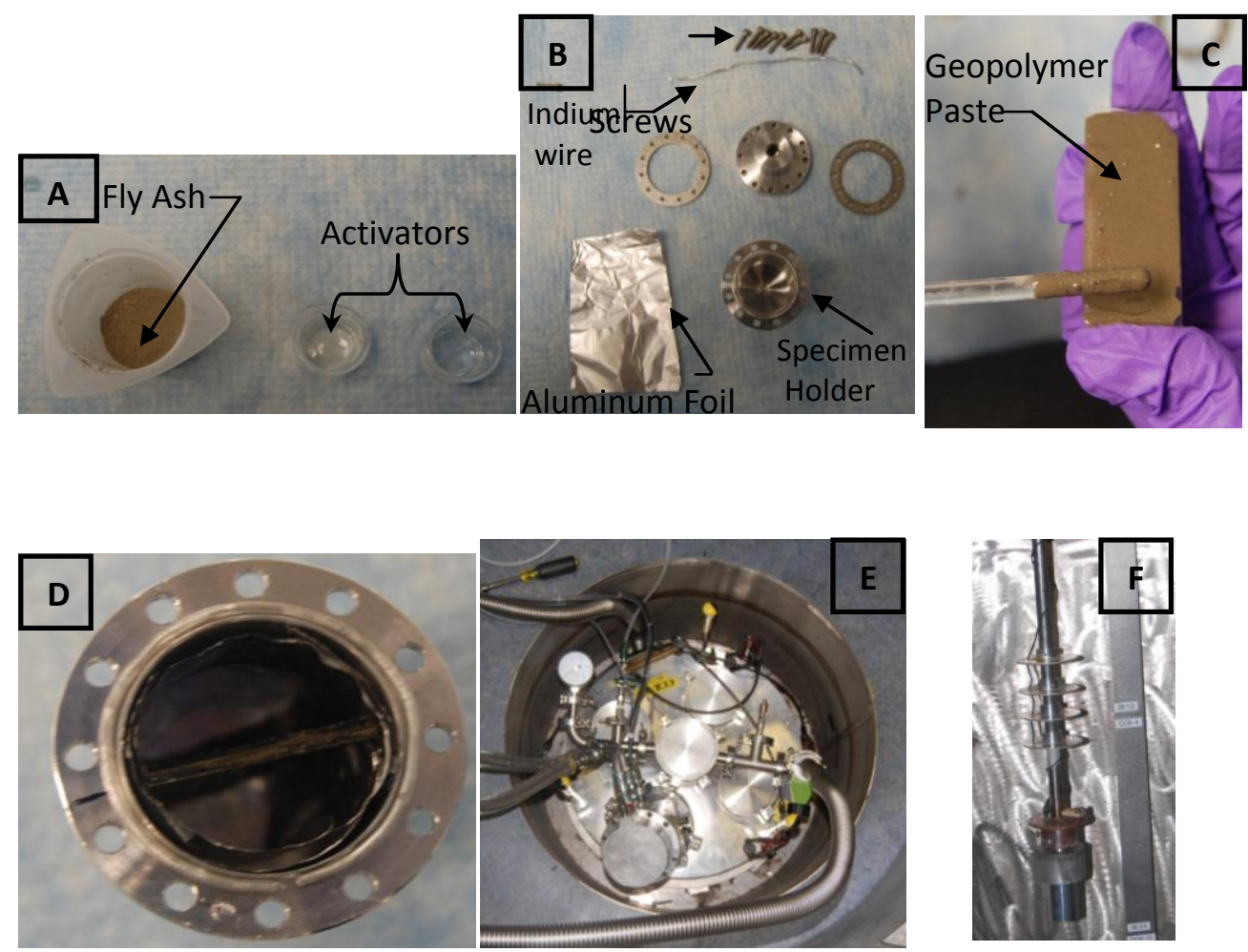

Fig 2. Preparation of Geopolymer paste and specimen setup a) Fly ash and activators, b) specimen holder and parts included for the setup. c) Geopolymer paste applied on the glass slide, d) Geopolymer paste sandwiched between two glass slides and inserted inside the specimen holder, e) BASIS Sample Environment (Close-Cycle Refrigerator (CCR) f) Specimen holder attached to the stick and ready to be inserted in CCR.

Table 1. Chemical composition of fly ashes obtained via XRF analysis

$$
\text { Component (mass \% as oxide) }
$$




\begin{tabular}{|c|c|c|c|c|c|c|c|c|c|c|c|c|c|}
\hline $\begin{array}{l}\text { Fly } \\
\text { ash } \\
\text { ID }\end{array}$ & $\mathrm{SiO}_{2}$ & $\mathrm{Al}_{2} \mathrm{O}_{3}$ & $\mathrm{CaO}$ & $\mathrm{Fe}_{2} \mathrm{O}_{3}$ & $\mathrm{MgO}$ & $\mathrm{SO}_{3}$ & $\mathrm{Na}_{2} \mathrm{O}$ & $\mathrm{TiO}_{2}$ & $\mathrm{MnO}_{2}$ & $\mathrm{~K}_{2} \mathrm{O}$ & $\mathrm{Mc}$ & LOI & $\begin{array}{c}\text { Type of } \\
\text { Ash }\end{array}$ \\
\hline $\mathrm{DH}$ & 58.52 & 20.61 & 5.00 & 9.43 & 1.86 & 0.49 & 0.52 & 1.09 & 0.16 & 1.89 & 0.14 & 0.17 & LCFA \\
\hline MO & 55.61 & 19.87 & 12.93 & 4.52 & 2.49 & 0.49 & 0.67 & 1.72 & 0.03 & 0.86 & 0.02 & 0.22 & HCFA \\
\hline
\end{tabular}

Mc: Moisture content, LOI: Loss on ignition at $1000^{\circ} \mathrm{C}$

152 HCFA: High calcium fly ash

153 LCFA: Low calcium fly ash

BASIS is an inverse geometry time-of-flight backscattering neutron spectrometer, in which high quality

156 Si (111) crystal analyzers are used to Bragg-select the final energy of the neutron $~ 2.08 \mathrm{meV}(6.27 \AA)$

157 after it scatters from the sample. For the present data analysis, a clean dynamic range from -100 to 100

$158 \mu \mathrm{eV}$ (free from spurious instrumental background) with a corresponding energy resolution of about 3.5

$159 \mu \mathrm{eV}$ (Full-Width-Half-Maximum) was used. At the time of our experiment, the proton accelerator was

160 stabilized around $850 \mathrm{~kW}$, which is about $60 \%$ of the future power upgrade of $1.4 \mathrm{MW}$. Nevertheless the

161 resulting neutron flux on the instrument was high enough to yield decent statistics over the time allocated

162 for this experiment. A flat cell geometry configuration was used for inserting samples at $135^{\circ}$ with respect

163 to incident neutron beam such that low angle detectors banks were in transmission mode. There is a total

164 of $112{ }^{3} \mathrm{He}$ detectors on the spectrometer, which monitor the scattering as a function of time and angular

165 position. The resulting Q-range covered in the present experiment was from 0.3 to $1.55 \AA^{-1}$, binned as

166 single spectra to improve statistics. For more details regarding the instrument, the reader is referred to

167 Mamontov and Herwig [6]. The data reduction and modeling of the data was performed using the

168 NIST DAVE software package[36].

169 Quasielastic neutron scattering technique is effective in tracking the immobile molecules, which

170 are dominated by the chemically bound water, and the constrained water during the hydration

171 process. Immobile molecules refers to hydrogen containing molecules considered stationary on

172 the assessable timescale of this instrument. QENS spectra, S(Q,E) represents the incoherent 
173 scattering from hydrogen $(\mathrm{S})$ as a function of energy change $(\omega)$ and scattering vector $(\mathrm{Q})$. The

174 scattering from a thin hollow vanadium cylinder was measured for normalization purposes over

175 the same Q-range. The scattering from a thin hollow vanadium (100\% incoherent) cylinder was

176 used to correct for fluctuations in the detector efficiency with changing Q. The amounts of

177 hydrogen in chemically bound, constrained and free water were determined at each time step (1

178 hour long runs) using a delta function (representing the immobile $\mathrm{H}$ atoms) and two Lorentzian

179 functions, which characterize respectively the dynamics of the confined or constrained water

180 molecules, and the free unrestricted bulk-like water component $[13,24,37]$. We denote by $\Gamma_{1}$ the

181 half-width at half-maximum (HWHM) of the slowly diffusing constrained water component and

182 by $\Gamma_{2}$ the HWHM of the free water. To account for instrument resolution effect at BASIS, we

183 measured a flat vanadium plate (which scatters incoherently) oriented in the same configuration as the

184 sample holders. Although the instrumental resolution function was found to be narrower than the

185 relevant signal, we use it to perform full numerical convolution for accuracy and precision. This

186 measured resolution $R(E)$ is directly convoluted with the following scattering model $S(E)$, which includes

187 contributions from water that is chemically bound (or static on the instrument window), water that

188 diffuses slowly due to the spatial confinement, and water that moves freely around [38],

$S(E)=C[\delta(E=0)]+P\left(\frac{\Gamma_{1}}{\pi\left(E^{2}+\Gamma_{1}^{2}\right)}\right)+F\left(\frac{\Gamma_{2}}{\pi\left(E^{2}+\Gamma_{2}^{2}\right)}\right)$

The intensities related to elastic scattering ( chemically bound), slow diffusion ( constrained water), and fast diffusion (highly mobile or free water) are denoted as $\mathrm{C}, \mathrm{P}$, and F, respectively. $\Gamma_{1}$ is the HWHM associated with the spatially constrained water and $\Gamma_{2}$ that of the free water. Both $\Gamma_{1}$ and $\Gamma_{2}$ are free adjustable fitting parameters in our fits. A sloping background term $\mathrm{B}(\mathrm{E})=\mathrm{aE}+\mathrm{b}$, although not included in the convolution, accounts for the baseline intensity, and improves the quality of the fits, A representative fitted QENS spectrum (1 hour long collection of high calcium content sample) for alkali activation reaction is shown in Figure 3. 


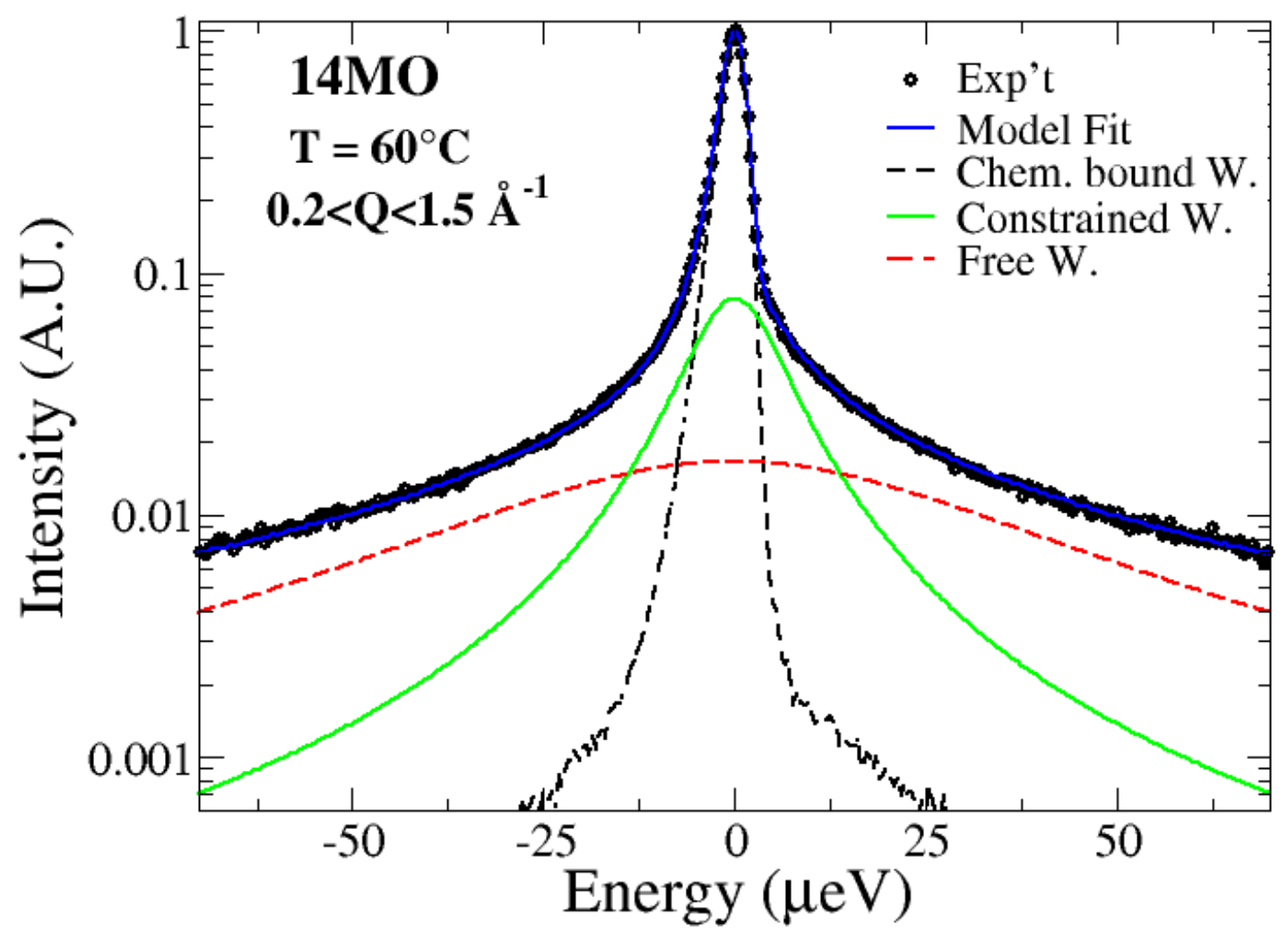

Fig 3. One hour-long neutron spectrum observed at BASIS for $14 \mathrm{M} \mathrm{NaOH}$ high calcium geopolymer paste (black circles) at $60^{\circ} \mathrm{C}$, summed over a wide range of $\mathrm{Q}$ (as indicated in the legend). The best full model fit (blue line) and the corresponding fit components representing respectively the freely diffusing bulk-like water (dashed red line), the slowly diffusing or constrained water (solid green line) and the chemically bound water (dashed black line) are also shown.

Using the three-component model described above, we calculate the bound water index (BWI) using [13],

$$
B W I=\left(\frac{C+P}{C+F+P}\right)
$$

which corresponds to the states of bond water or the relative amount of bound water molecules, including those slowly moving molecules. Conversely, we can calculate the free water index (FWI) using,

$$
F W I=1-B W I=\frac{F}{C+F+P}
$$

\section{Results and Discussion}


213 The quasielastic neutron spectra of geopolymer paste prepared with the low calcium fly ash (DH) is

214 shown in Figure 4. This data shows the effect of neutron scattering intensity at various temperatures and

215 at initial (approximately 5 minutes was taken to prepare the sample, load and open the shutter for neutron

216 beam exposure), while the later time was measured 10 hours later. "Initial time" indicates as soon as the

217 paste was alkali activated and the exact temperature was stabilized. Figure 4 indicates a significant change

218 between the initial QENS line shape at 20 and $60^{\circ} \mathrm{C}$ and their corresponding line shape after 10 hours.

219 Application of heat caused significant broadening of the QENS wings that can be attributed to the

220 movement of water molecules, both constrained and free water. However, as the geopolymer paste starts

221 to react, the elastic component (energy transfer E=0) starts to increase over time, and the broad QENS

222 signal $(\mathrm{E} \neq 0)$ decreases. We observed similar behavior at other temperatures, therefore capturing the

223 kinetics of the paste reactions. The activation kinetics indicate the transition from liquid to solid state with

224 the nucleation to polymerization finally leading to the hardened cement paste [1, 39].

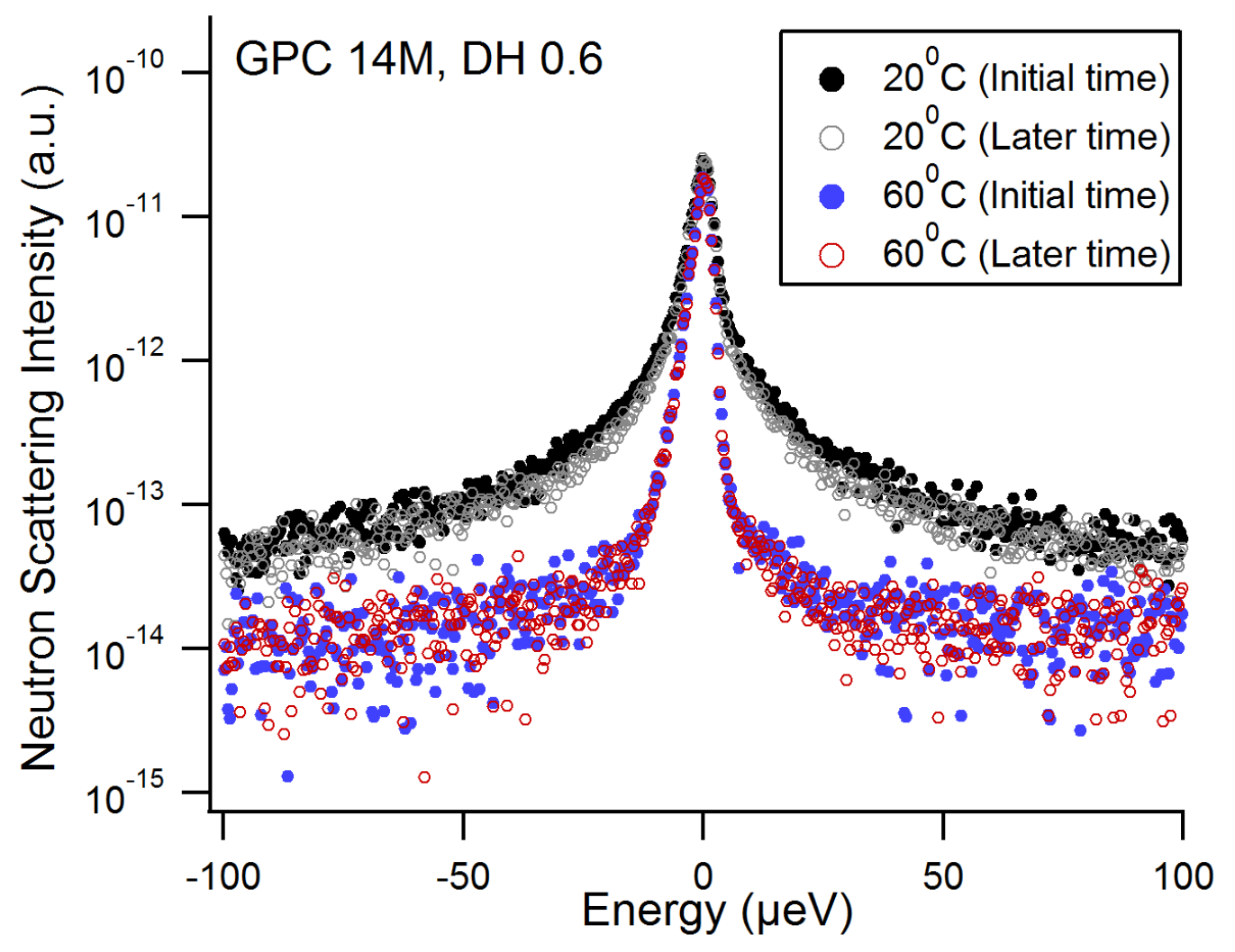


Fig 4. Time evolution quasielastic neutron response of Geopolymer paste prepared with low calcium fly ash $(\mathrm{DH})$ at $20^{\circ} \mathrm{C}$ and $60^{\circ} \mathrm{C}$. Spectra shown are 10 minutes long. 'Initial' and 'later' refer respectively to the time when the specimen was prepared and 10 hours later. In-situ geopolymer pastes were maintained at $60^{\circ} \mathrm{C}$ and $20^{\circ} \mathrm{C}$, while the measurements were taken at a 231 time step of 10 and 3 minutes for $60^{\circ} \mathrm{C}$ and $20^{\circ} \mathrm{C}$, respectively as shown in Figure 5. To increase the 232 statistical quality of these short runs for use in the data analysis, we binned $\sim 6$ successive short $\sim 10$ 233 minutes counts spectra into 1 hour-long spectrum. The HWHM $\Gamma_{1}$ in these summed QENS spectra for 234 high calcium content Geopolymer paste at $20^{\circ} \mathrm{C}$ remains unchanged from its value at $\sim 3.7 \mu \mathrm{eV}$ in the first $2351 / 2$ hour of the data collection up to 12 hours later. In contrast, the same $\Gamma_{1}$ at $60^{\circ} \mathrm{C}$ is observably broader 236 and appears to change sligthly from $(6.5 \pm 0.25) \mu \mathrm{eV}$ in the first $1 / 2$ hour down to $(5 \pm 025) \mu \mathrm{eV}$ in the 8 $2379^{\text {th }}$ hour after which it stays more or less constant $(\sim 5 \mu \mathrm{eV})$ for the duration of the experiment (See Figure 238 9). This apparent change may be associated with the decrease in the parameter $\mathrm{P}$ with time, which 239 complicates the extraction of $\Gamma_{1}$ at longer time. Thes observations indicate that the temperature plays a 240 vital role in controlling the setting and hardening of geopolymer pastes. In addition, this shows that the 241 free water in the pore solution is significantly reduced and the temperature has expedited the formation of 242 bound hydrogen. Heat thus plays a crucial role in controlling the geopolymer mechanism and expedites 243 the re-organization and hardening process of geopolymer cements [7], in agreement with previous studies $244[40]$. 

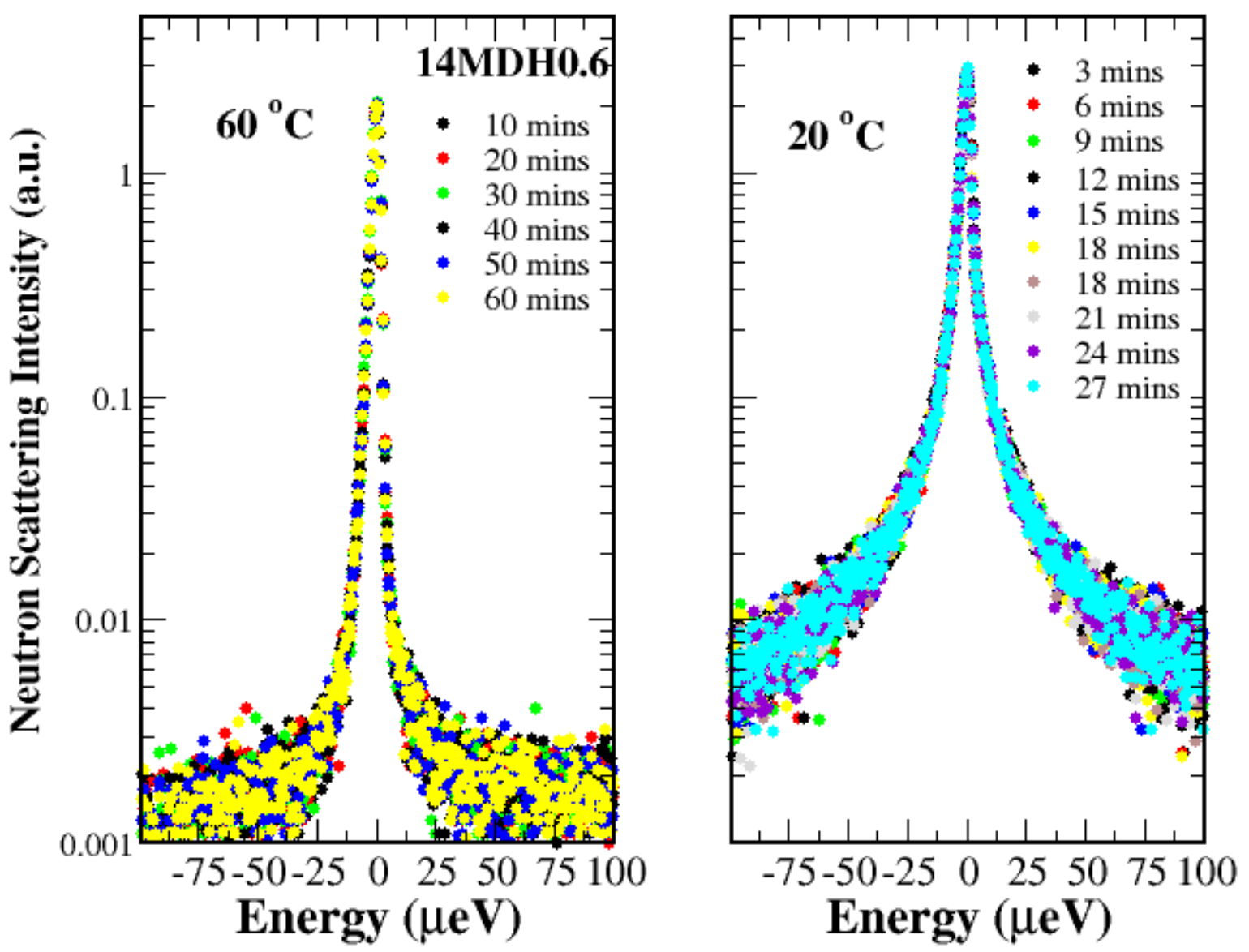
increases.

Fig 5. Quasielastic neutron spectra of geopolymer paste at $60^{\circ} \mathrm{C}$ and $20^{\circ} \mathrm{C}$ prepared with low Calcium Fly Ash (Geopolymer paste-DH). The spectra shown were collected over fairly short period of times, respectively 10 minutes (left panel), and 3 minutes long (right panel), to track the time evolution of the elastic intensity.

Geopolymer prepared with high calcium fly ash (MO) and alkali activated with $14 \mathrm{M} \mathrm{NaOH}$ solution is shown in Figure 6. The energy resolved QENS spectra shows the variation of neutron scattering intensity with time. This figure indicates the time slice just after mixing until some 15 hours later. It can be clearly seen that the QENS broadening decreases with increasing time, while the elastic component 


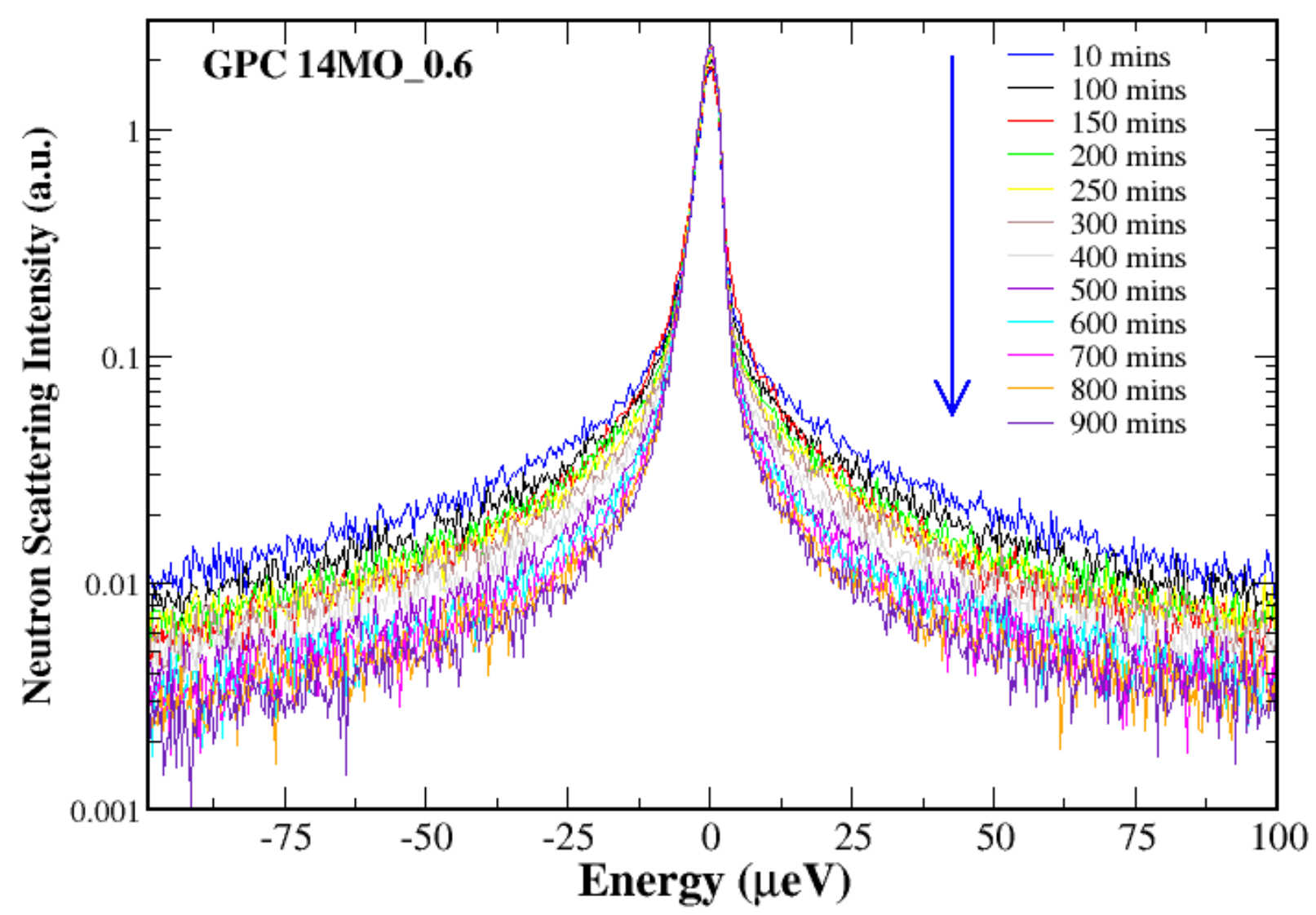

Fig 6. Neutron Scattering Intensity with increment with time for Geopolymer paste prepared with High Calcium Fly ash and $14 \mathrm{M}$ sodium hydroxide solution. These spectra represent snapshots of the scattering intensity in time, collected for about 10 minutes at each timestep.

The time dependence of the maximum elastic intensity of geopolymer paste prepared with high calcium fly ash and alkali activated using $14 \mathrm{M} \mathrm{NaOH}$, which was cured at $60^{\circ} \mathrm{C}$ and ambient temperature is shown in Figure 7. As soon as the fly ash is alkali activated and kept at $60^{\circ} \mathrm{C}$ the dissolution phase is initiated and elastic intensity increases till $\sim 150^{\text {th }}$ min. The gelation phase can be associated with the drop in elastic intensity, which occurs at around $210^{\text {th }}$ minutes followed by reorganization which then leads to polymerization and hardening [7, 10]. Reorganization and hardening are an ongoing process and depends on factors such as particle size distribution of the fly ash, loss of ignition, calcium oxide content and crystalline to amorphous ratio. The geopolymer paste prepared with high calcium fly ash (MO) and ambient cure did not exhibit any significant increase in elastic intensity as shown in Figure 7. This may 
be due to limitations of the machine (Backscattering spectrometer, BASIS) or the reaction mechanism may be too rapid for BASIS. Further research is required and use of other instruments (having broader

278 dynamic range) such as the Cold Neutron Chopper Spectrometer (CNCS) is necessary to capture faster 279 reactions, during the initial activation process. Unfortunately due to neutron kinematics and engineering 280 constraint, there is no single neutron instrument that is capable of probing all (Q,E) space in a single shot. 281 BASIS is only optimized to investigate slow dynamical process at molecular length scale (0.3 to $3 \mathrm{~nm})$.

282 Other instruments are required to access dynamics outside this range.

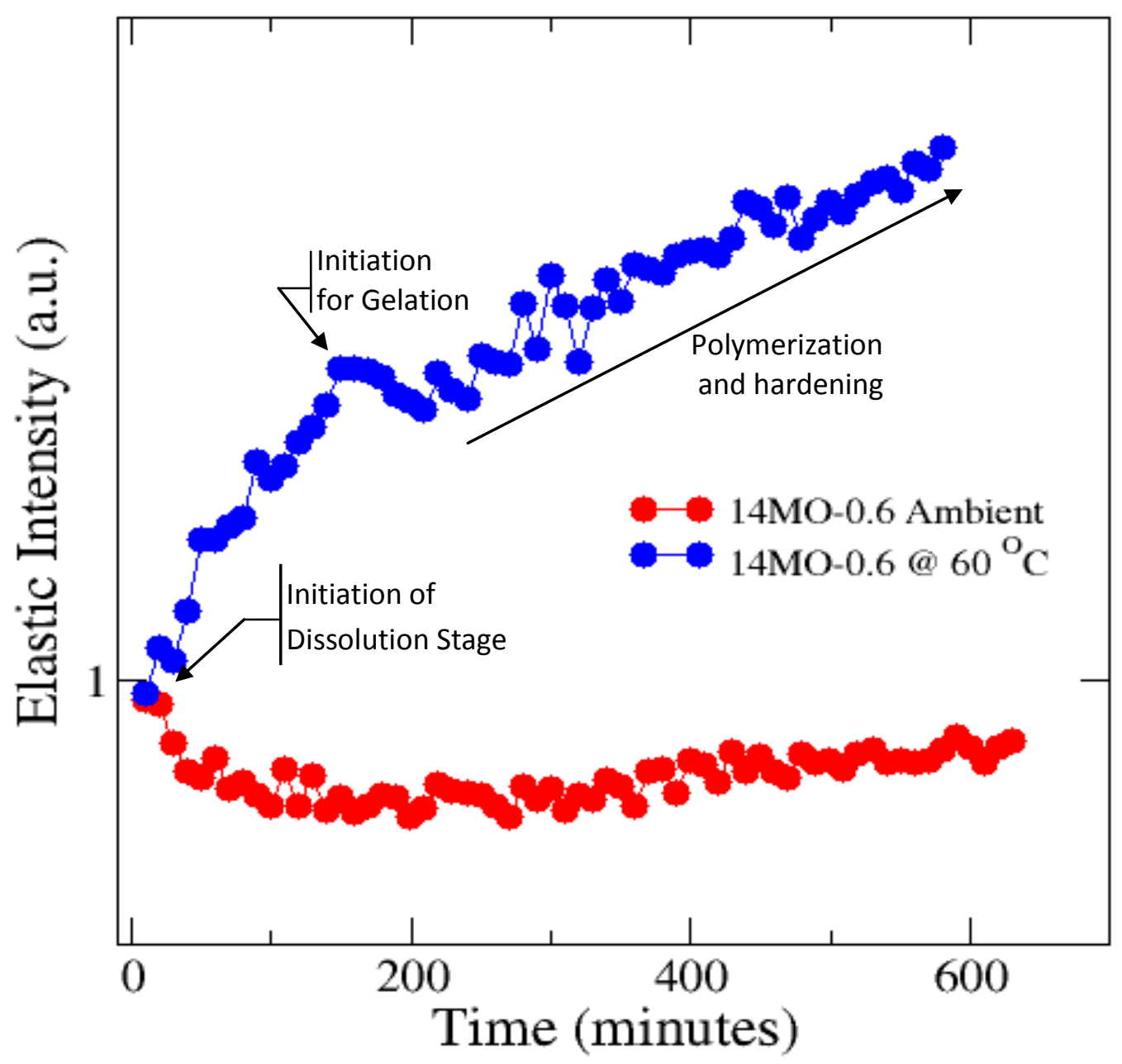

Fig 7. Elastic Intensity normalized to the intensity initial of geopolymer paste prepared with high calcium Geopolymer paste with $14 \mathrm{M} \mathrm{NaOH}$ concentration. 

solution is shown in Figure 8. Geopolymer paste was prepared with high calcium fly ash (MO) when 292 subject to $60^{\circ} \mathrm{C}$ exhibited an almost similar trend as shown by geopolymer paste at $14 \mathrm{M} \mathrm{NaOH}$. In our 293 opinion, this process was initiated by dissolution phase followed by gelation at 190 minutes. We attribute 294 the slight drop in elastic intensity to the initiation of gelation. Studies have shown that when fly ash is 295 activated with sodium hydroxide a lag period is observed before the re-organization process [39]. This 296 behavior indicates the time taken to form stable nuclei before the initiation of the growth, which is 297 characterized by an increase in intensity with time. The indication of the lag period is attributed to initial 298 preferential dissolution of alumina from the fly ash that initiates a siliceous layer on the fly ash. 299 Adsorption of aqueous $\mathrm{Al}$ species on the surface causes the surface to passivate by inhibiting the approach of hydroxyl ions which slows the dissolution process [41]. Over a time period the retarded dissolution process slowly releases sufficient silica to react with aqueous alumina to stop the inhibition. This process accelerates the dissolution of fly ash leading to a formation of gel network. The gelation process was followed by the re-organization leading to polymerization and hardening of the paste. A significant change in the elastic intensity was observed during the re-organization phase for geopolymer paste prepared with $14 \mathrm{M} \mathrm{NaOH}$ solution as compared with $10 \mathrm{M} \mathrm{NaOH}$ solution (see Figure 7). This strong variation could be attributed to leaching mechanism when higher molartiy of alkali activated solution is used in preparation of geopolymer paste. Independent studies based on other techniques such as small angle neutron/X-ray scattering techniques are required for better understandings the leaching mechanism.

The gelation and polymerization trend was not clearly visible in the low calcium geopolymer paste (DH), 311 while the high calcium geopolymer paste (MO) when subjected to $60^{\circ} \mathrm{C}$ exhibited the gelation and 312 polymerization stage. One possible reason could be the reaction in low calcium geopolymer paste occurs 313 much rapidly than the BASIS instrument can record. Further studies using cold neutron chopper 314 spectrometer (CNS) or high flux backscattering spectrometer (HFBS) may be necessary to capture alkali315 activation reactions using low calcium geopolymer pastes. This study shows that high calcium 

which was not possible at ambient temperature.

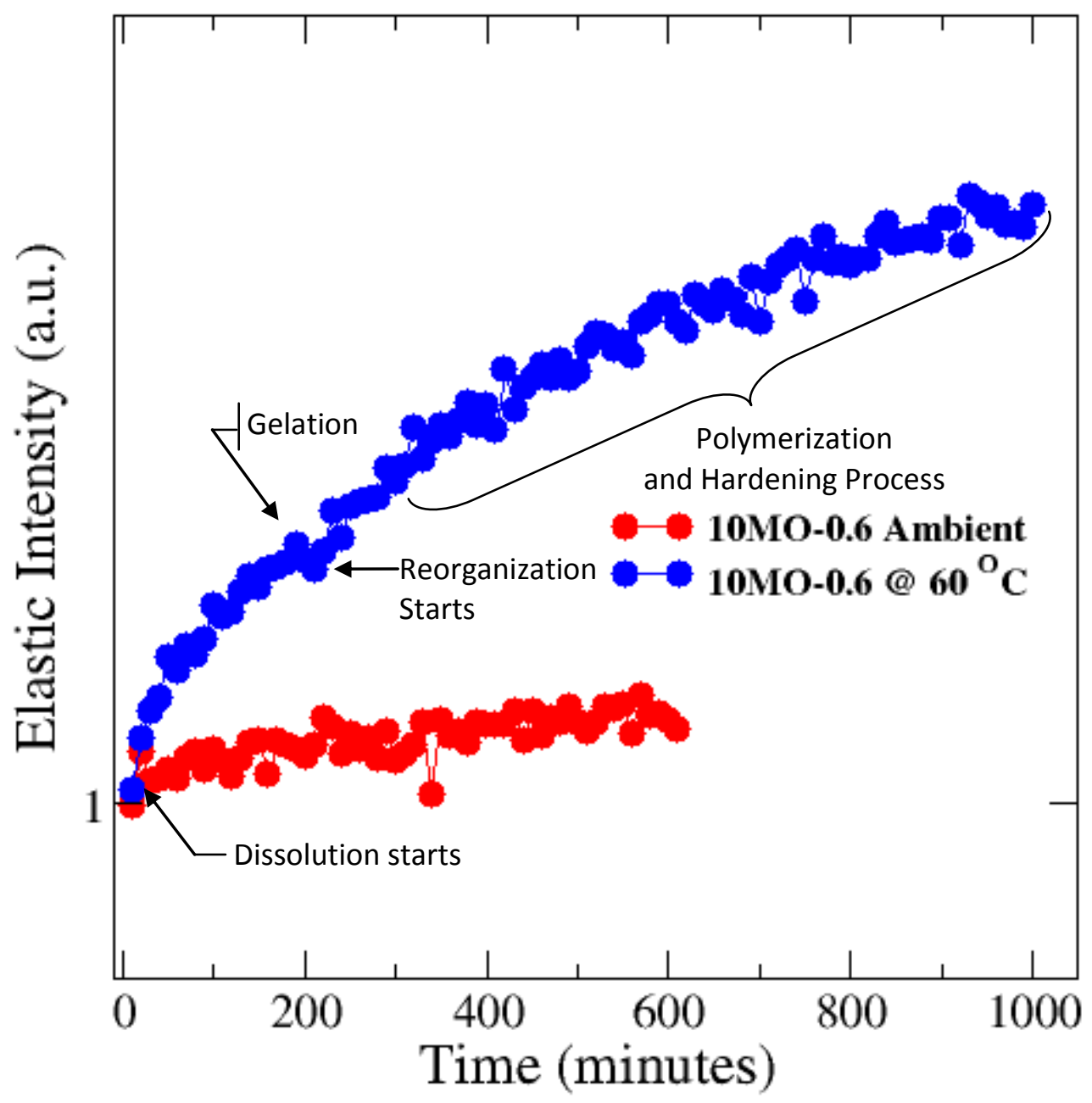

Fig 8. Elastic Intensity of Geopolymer paste prepared with High calcium fly ash with $10 \mathrm{M} \mathrm{NaOH}$ concentration.

Free-Water-Index (FWI) for high calcium fly ash geopolymer prepared with $10 \mathrm{M}$ and $14 \mathrm{M} \mathrm{NaOH}$ was calculated using Equation 3, and displayed in the top panel of Figure 9. An alternative FWI in which only the truly free water (F) is considered is also shown for comparison. In both cases, FWI clearly decreases with time, indicating that free water is being utilized during the geopolymer reaction to form either chemically bound water or spatially constrained water. Gelation can be observed in the range of $0-8$ hours, as a continuous drop of the FWI, indicating steady reduction in free water with time. The change in 
slope after $\sim 8$ hours shows a drastic change in the free water reduction rate. This is consistent with

Figures 7 and 8 where a gradient shift in elastic intensity was observed with increasing time. A steady decrease in FWI indicates an increase in gelation, which we associate with reorganization and polymerization driven hardening of the geopolymer cement paste. Geopolymer paste prepared with 14M $\mathrm{NaOH}$ solution exhibited a slightly higher decrease in intensity as compared to the pastes prepared with $10 \mathrm{M} \mathrm{NaOH}$ concentration over the time period probed. This indicates that the higher the molarity of activator $(\mathrm{NaOH})$ the greater the free water is being utilized in the reaction, for the formation of chemically bound water. At same temperature conditions, molarity of the activator plays a crucial role in governing and expediting the hardening mechanism of geopolymer cement pastes.

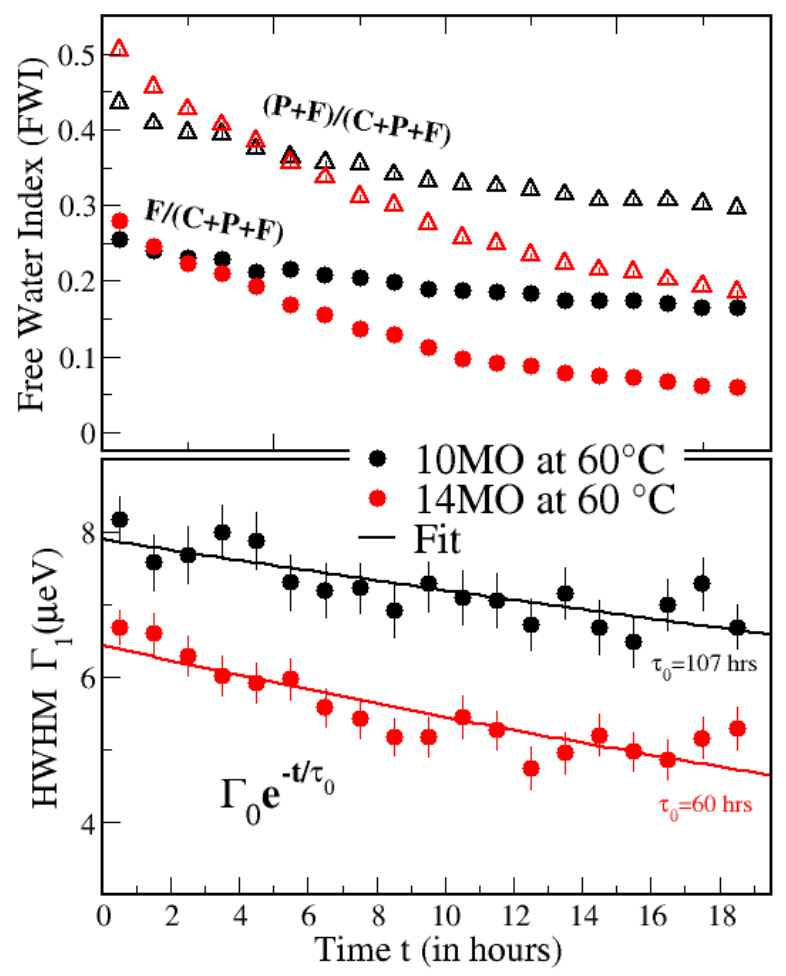

Fig 9. Top panel: Free water index for high calcium Fly ash geopolymer paste prepared with 10 and $14 \mathrm{M}$ $\mathrm{NaOH}$ solution and cured at $60^{\circ} \mathrm{C}$, depending on whether the constrained water (open symbols) is included or not (solid symbols). Bottom Panel: Corresponding width parameter HWHM as a function of time for the $10 \mathrm{M} \mathrm{NaOH}$ (black circles) and $14 \mathrm{M} \mathrm{NaOH}$ (red circles) geopolymer pastes. The decay rates shown are derived from fits (solid lines) to the exponential decay function indicated, and correspond to 
the times the constrained water $\left(\Gamma_{1}\right)$ would remain observable on the BASIS instrument, based on the observed trend.

The bottom panel of Figure 9 shows the time dependence of the fitted width $\Gamma_{1}$ for our two compounds at $60^{\circ} \mathrm{C}$. It is interesting to note that the $10 \mathrm{M} \mathrm{NaOH}$ high $\mathrm{Ca}$ fly ash exhibits $\Gamma_{1}$ values that are somewhat larger than those of the $14 \mathrm{M}$ compound. Assuming an exponentially decay rate for $\Gamma_{1}$, we get a time constant of respectively $\sim 107$ and 60 hours for the $10 \mathrm{M}$ and $14 \mathrm{M}$ samples, respectively, confirming that hardening will occur much faster in the $14 \mathrm{M}$. These derived values correspond roughly to the times the constrained water $\left(\Gamma_{1}\right)$ would remain observable on BASIS (from the time the sample is prepared), or the time by which all of the discernible constrained water molecules (or P parameter) would transfer to the chemically bound side ( $\mathrm{C}$ parameter). Additionally, the fitted $\Gamma_{2}$ characterizing the free water, are found to be largely independent of time, staying approximately at $\sim 50 \mu \mathrm{eV}$ in the $10 \mathrm{M}$ sample compared to $\sim 35$ $\mu \mathrm{eV}$ in the $14 \mathrm{M}$ at $60^{\circ} \mathrm{C}$ at all time investigated here. Based on this observation, we can conclude that the free water component appears to be much more mobile in the $10 \mathrm{M}$ than in the $14 \mathrm{M}$ compound at the same temperature. For this reason, a neutron instrument with coarser resolution would be more suitable for tracking water behavior in the $10 \mathrm{M}$ compound.

The current study cannot predict new reaction mechanism as the structure of the gel formed needs to be recognized and examined. Additional characterization is required to study the structure of these gels using small angle neutron/X-Ray scattering. It is attributed to the possible formation of the sodium alumino silicate hydrate (N-A-S-H) gels, while separate study is required to analyze the behavior of N-A-S-H gels using QENS technique. Although, the reaction mechanisms of geopolymeric gels are different compared to Portland cements, in case of geopolymer gel depending on the type of activation, we observe Sodium Aluminiosilicate Hydrate (N-A-S-H) or Calcium, Sodium alumino silicate hydrate (C-N)-A-S-H gels [42]. This work focuses on tracking the free water during geopolymerization and, suggest that some amount of heat is necessary for initiating the onset of gelation. However, that the movement of water inside the geopolymeric gel is difficult to 
369 quantify with QENS because the amount of water diffusing is continuously evolving with time,

370 and data can not be collected in the steady state with sufficient statistics to get the required Q

371 information. Future work is thus required to confirm the diffusion coefficients using for example

372 NMR relaxometry.

373 This study focus on the early age behavior during the activation process which leads to these gels by 374 bonding of the hydrogen atoms which then precipitates form the geopolymeric gel. Chemically bound and 375 constrained form of water is shown in Figure 10 as a percentage of bound water states. High calcium fly 376 ash was activated with 10 and $14 \mathrm{M}$ sodium hydroxide solution cured at $60^{\circ} \mathrm{C}$. This BWI quickly reaches $377 \sim 50 \%$ within the first hour in both samples (with a slightly higher value with the $10 \mathrm{M}$ sample). The 378 remainder $50 \%$ water takes several hours to bind to the cementitious gel structure. The BWI increases 379 steadily to about $60 \%$ after $4-5$ hours. Beyond this point, the amount of chemically bound water 380 molecules increases faster in the $14 \mathrm{M}$ sample than in the $10 \mathrm{M}$ one, likely due to the higher gelation rate 381 in the $14 \mathrm{M}$. Following an additional 5 hours, both curves start to flatten to a constant value. The 382 percentage of constrained water changes little with time, starting at 18-20\% at time zero and ending at 13$38314 \% 19$ hours later for both samples. This decrease is in part responsible for the increase in the amount of 384 chemically bound water molecules. 


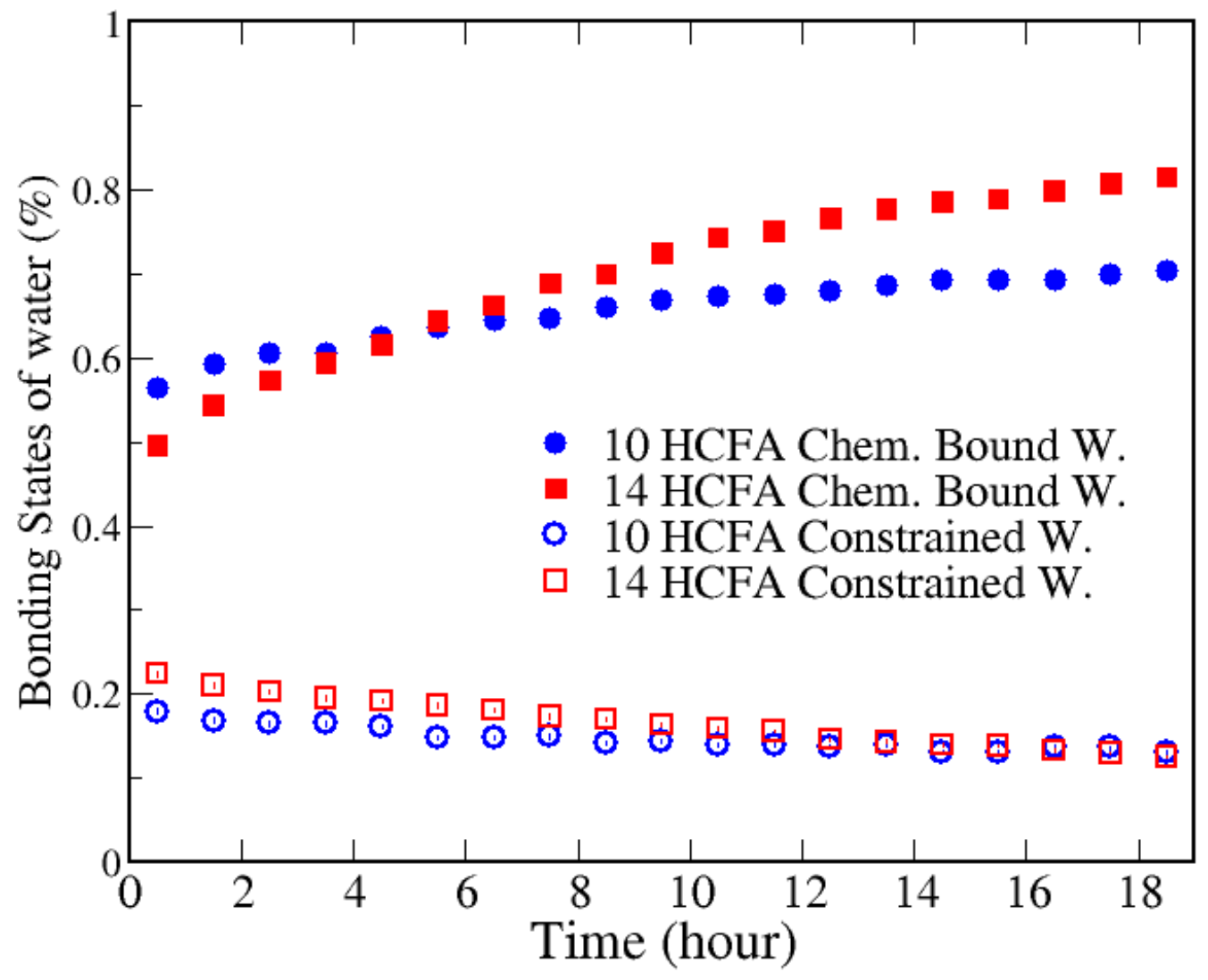

Fig 10. Estimated water bonding states of the $10 \mathrm{M}$ and $14 \mathrm{M}$ geopolymer pastes with 0.6 activator/binder ratio and cured at $60^{\circ} \mathrm{C}$. The solid symbols refer to the chemically bound water $(\sim \mathrm{C}$ parameter) and the open symbols are the spatially constrained water in the paste ( $\sim \mathrm{P}$ parameter).

The constrained water for the geopolymer pastes activated with 10 and $14 \mathrm{M}$ was less than the chemically bound water. This can be associated to initiation of gelation and growth that can increase chemically 392 bound water $[14,43,44]$. These results are in conjunction of the work conducted by Rees et. al [39, 45, 393 46]. These results show that an initial lag period between 2-3 hours s followed by evolution of gelation 394 for high calcium geopolymer paste (MO) activated with $14 \mathrm{M}$ concentration. An increase in network 395 formation was associated with an increase in $\mathrm{NaOH}$ solution, as compared to fly ash activated using $10 \mathrm{M}$ 396 concentration. This behavior can be attributed to the increased alkalinity due to high molar concentration accompanied by strong ion-paring that allows greater number of hydrogen atoms to be fixed. The 
increased molarity only contributes to a certain point and after that it is followed by a reduction in the gel network accompanied by the reorganization process which is dependent on heat curing.

400

401

402

403

404

405

406

407

408

409

410

411

412

413

414

415

416

417 of certain geopolymeric gels.

\section{Conclusions} dependent.

High and low calcium fly ash based geopolymer pastes were studied using in-situ QENS technique. During the alkali activation process the transition from liquid to solid state was observed via nucleation of the gels leading to reorganization and polymerization when subject to $60^{\circ} \mathrm{C}$. This reaction mechanism was not observed on geopolymer pastes at ambient temperature. Geopolymer pastes prepared with $14 \mathrm{M}$ concentration showed higher chemically bond water as compared to pastes prepared with $10 \mathrm{M}$ concentration. Molarity of $\mathrm{NaOH}$ and curing temperature together play a vital role in the formation of initial geopolymer gels and polymerization at the later stage of the reaction. This study shows that the high calcium geopolymers are more suitable for gelation and the activation process is temperature

During the initial activation period the chemically bound and constrained water increases, upon initiation of nucleation and growth period the constrained water remained approximately constant. The initial increase in constrained water could be attributed to the decrease in total surface area and starts to retard as the conversion to gel pores are formed due the decrease in the volume of the surface area. Overall quasielastic neutron scattering is an effective technique for studying the early age dynamic characteristics 


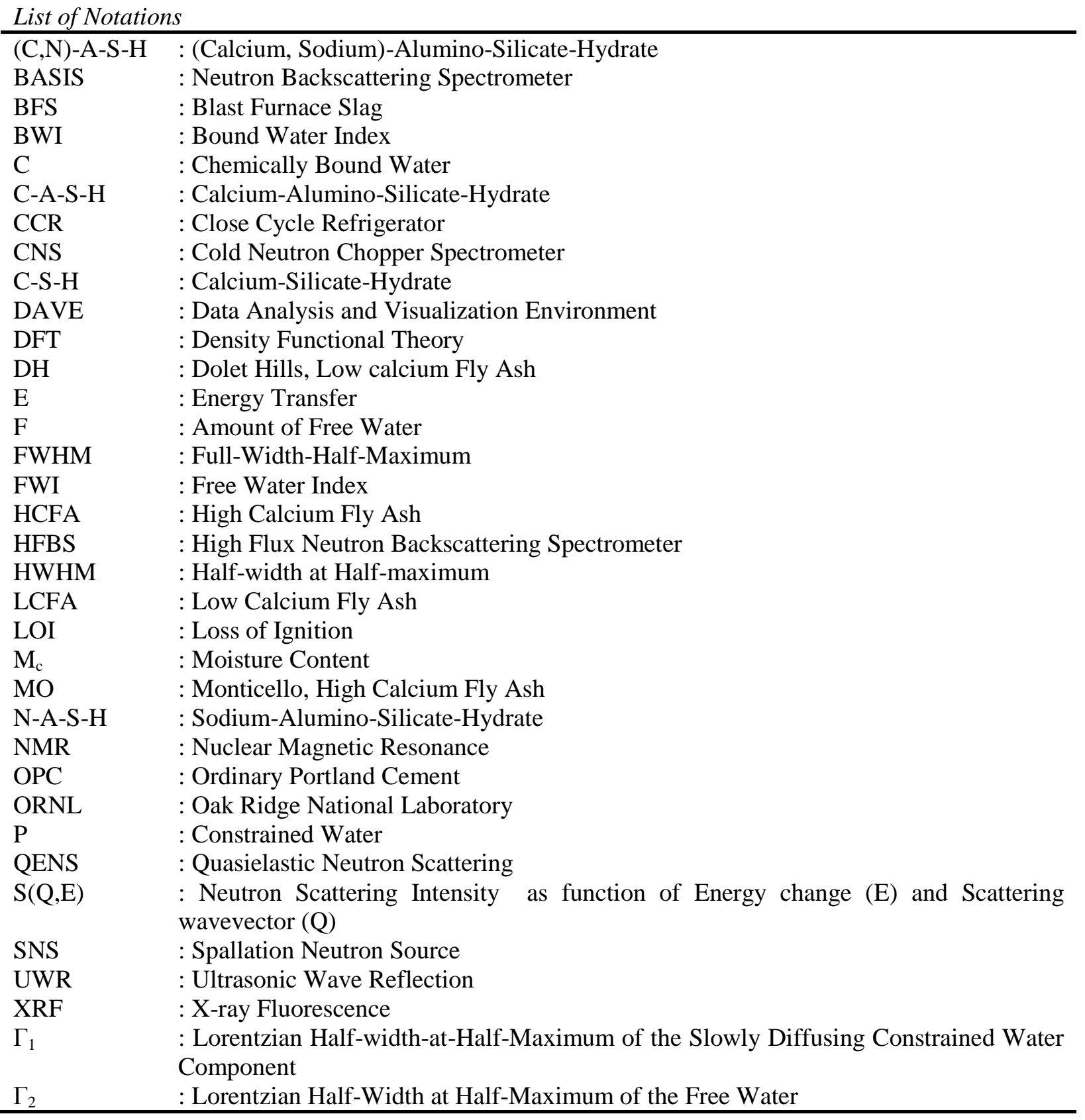

428 Acknowledgement

430 This research at ORNL's Spallation Neutron Source (SNS) was sponsored by the Scientific User Facilities

431 Division, Office of Basic Energy Sciences, U.S. Department of Energy. Travel to Oak Ridge National

432 Laboratory to carry out this work was supported by a Travel Fellowship from the DOE-EPSCoR Grant to 

the paper was at Louisiana Tech University. We would like to thank Dr. Eugene Mamontov from Oak Ridge National Laboratory for fruitful discussions during the course of these experiments. The authors are also thankful to Dr. Claire White from Princeton University for reviewing the initial version of this manuscript and for her feedback.

438

439

440

441

442

443

444

445

446

447

448

449

450

451

452

453

454

455

456

457

458

459

460

461

462

463

464

465

466

467

468

469

470

471

472

473

474

\section{References}

[1] J.L. Provis, J.S.J. Van Deventer, Geopolymers: Structure, Processing, Properties and Industrial Applications, Woodhead Publishing Limited2009.

[2] A.R. Sakulich, Reinforced geopolymer composites for enhanced material greenness and durability, Sustainable Cities and Society 1(4) (2011) 195-210.

[3] P. Duxson, A. Fernández-Jiménez, J. Provis, G. Lukey, A. Palomo, J. van Deventer, Geopolymer technology: the current state of the art, J Mater Sci 42(9) (2007) 2917-2933.

[4] P. Duxson, J.L. Provis, Designing Precursors for Geopolymer Cements, Journal of the American Ceramic Society 91(12) (2008) 3864-3869.

[5] P. Duxson, J.L. Provis, G.C. Lukey, S.W. Mallicoat, W.M. Kriven, J.S.J. van Deventer, Understanding the relationship between geopolymer composition, microstructure and mechanical properties, Colloids and Surfaces A: Physicochemical and Engineering Aspects 269(1-3) (2005) 47-58.

[6] E. Mamontov, K.W. Herwig, A time-of-flight backscattering spectrometer at the Spallation Neutron Source, BASIS, Review of Scientific Instruments 82(8) (2011) -.

[7] J. Provis, Geopolymers and other alkali activated materials: why, how, and what?, Mater Struct 47(12) (2014) 11-25.

[8] J. Davidovits, Synthetic Mineral Polymer Compound of the Silicoaluminates, 1984.

[9] J. Davidovits, Geopolymer Chemistry and Applications, Institut Géopolymère2011.

[10] J.L. Provis, J.S.J. van Deventer, Geopolymerisation kinetics. 2. Reaction kinetic modelling, Chemical Engineering Science 62(9) (2007) 2318-2329.

[11] J. Provis, Geopolymers and other alkali activated materials: why, how, and what?, Mater Struct (2013) 1-15.

[12] P. Duxson, A. Fernández-Jiménez, J.L. Provis, G.C. Lukey, A. Palomo, J.S.J. Deventer, Geopolymer technology: the current state of the art, J Mater Sci 42(9) (2007) 2917-2933.

[13] V. Peterson, Studying the Hydration of Cement Systems in Real-time Using Quasielastic and Inelastic Neutron Scattering, in: G. Eckold, H. Schober, S.E. Nagler (Eds.), Studying Kinetics with Neutrons, Springer Berlin Heidelberg2010, pp. 19-75.

[14] T. Gutberlet, H. Hilbig, R.E. Beddoe, W. Lohstroh, New insights into water bonding during early tricalcium silicate hydration with quasielastic neutron scattering, Cement and Concrete Research 51 (2013) 104-108.

[15] J.W. Phair, J.C. Schulz, W.K. Bertram, L.P. Aldridge, Investigation of the microstructure of alkaliactivated cements by neutron scattering, Cement and Concrete Research 33(11) (2003) 1811-1824. 
[16] H.N. Bordallo, L.P. Aldridge, A. Desmedt, Water Dynamics in Hardened Ordinary Portland Cement Paste or Concrete: From Quasielastic Neutron Scattering, The Journal of Physical Chemistry B 110(36) (2006) 17966-17976.

[17] H.N. Bordallo, L.P. Aldridge, P. Fouquet, L.C. Pardo, T. Unruh, J. Wuttke, F. Yokaichiya, Hindered Water Motions in Hardened Cement Pastes Investigated over Broad Time and Length Scales, ACS Applied Materials \& Interfaces 1(10) (2009) 2154-2162.

[18] S.A. FitzGerald, D.A. Neumann, J.J. Rush, D.P. Bentz, R.A. Livingston, In Situ Quasi-elastic Neutron Scattering Study of the Hydration of Tricalcium Silicate, Chemistry of Materials 10(1) (1998) 397-402.

[19] E. Fratini, S.-H. Chen, P. Baglioni, Investigation of the Temporal Evolution of Translational Dynamics of Water Molecules in Hydrated Calcium Aluminate Pastes, The Journal of Physical Chemistry B 107(37) (2003) 10057-10062.

[20] E. Fratini, S.-H. Chen, P. Baglioni, M.-C. Bellissent-Funel, Quasi-Elastic Neutron Scattering Study of Translational Dynamics of Hydration Water in Tricalcium Silicate, The Journal of Physical Chemistry B 106(1) (2001) 158-166.

[21] J.W. Phair, R.A. Livingston, C.M. Brown, A.J. Benesi, Investigation of the State of Water in Hydrating Layered Sodium Disilicate in Crystalline and Amorphous Forms by Quasi-Elastic Neutron Scattering, Chemistry of Materials 16(24) (2004) 5042-5050.

[22] F. Ridi, P. Luciani, E. Fratini, P. Baglioni, Water Confined in Cement Pastes as a Probe of Cement Microstructure Evolution, The Journal of Physical Chemistry B 113(10) (2009) 3080-3087.

[23] A.R. Benetti, J. Jacobsen, B. Lehnhoff, N.C.R. Momsen, D.V. Okhrimenko, M.T.F. Telling, N. Kardjilov, M. Strobl, T. Seydel, I. Manke, H.N. Bordallo, How mobile are protons in the structure of dental glass ionomer cements?, Scientific Reports 5 (2015) 8972.

[24] V.K. Peterson, C.M. Brown, R.A. Livingston, Quasielastic and inelastic neutron scattering study of the hydration of monoclinic and triclinic tricalcium silicate, Chemical Physics 326(2-3) (2006) 381-389.

[25] I. Garcia-Lodeiro, A. Palomo, A. Fernández-Jiménez, D.E. Macphee, Compatibility studies between $\mathrm{N}-\mathrm{A}-\mathrm{S}-\mathrm{H}$ and $\mathrm{C}-\mathrm{A}-\mathrm{S}-\mathrm{H}$ gels. Study in the ternary diagram Na2O-CaO-Al2O3-SiO2-H2O, Cement and Concrete Research 41(9) (2011) 923-931.

[26] C. Shi, A.F. Jiménez, A. Palomo, New cements for the 21st century: The pursuit of an alternative to Portland cement, Cement and Concrete Research 41(7) (2011) 750-763.

[27] P. Duxson, G. Lukey, J.J. Deventer, Physical evolution of Na-geopolymer derived from metakaolin up to $1000^{\circ} \mathrm{C}$, J Mater Sci 42(9) (2007) 3044-3054.

[28] J.I. Escalante-García, A.F. Fuentes, A. Gorokhovsky, P.E. Fraire-Luna, G. Mendoza-Suarez, Hydration Products and Reactivity of Blast-Furnace Slag Activated by Various Alkalis, Journal of the American Ceramic Society 86(12) (2003) 2148-2153.

[29] A. Fernández-Jiménez, F. Puertas, I. Sobrados, J. Sanz, Structure of Calcium Silicate Hydrates Formed in Alkaline-Activated Slag: Influence of the Type of Alkaline Activator, Journal of the American Ceramic Society 86(8) (2003) 1389-1394.

[30] K. Kupwade-Patil, F. Soto, A. Kunjumon, E.N. Allouche, D.S. Mainardi, Multi-scale modeling and experimental investigations of geopolymeric gels at elevated temperatures, Computers \& Structures 122(0) (2013) 164-177.

[31] P. Suraneni, S. Puligilla, E. Kim, X. Chen, L. Struble, P. Mondal, Monitoring Setting of Geopolymers, Advances in Civil Engineering Materials 3(1) (2014) 177-192.

[32] M. Dhakal, K. Kupwade-Patil, E.N. Allouche, C.C.I.B. Johnson, K. Ham, Optimization and Characterization of Geopolymer Mortars using Response Surface Methodology, Developments in Strategic Materials and Computational Design IV, John Wiley \& Sons, Inc.2013, pp. 135-149.

[33] A. C191, Standard Test Method for Time of Setting of Hydraulic Cement by Vicat Needle, ASTM International West Conshohocken, Pa., 1999. 
[34] C.-W. Chung, P. Suraneni, J.S. Popovics, L.J. Struble, Setting time measurement using ultrasonic wave reflection, ACI Materials Journal 109(1) (2012) 109-117.

[35] ASTM, ASTM D 4326-13 Standard Test Method for Major and Minor Elements in Coal and Coke Ash By X-Ray Fluorescence, ASTM International, West Conshohocken, PA, 2013, p. 4.

[36] R.T. Azuah, L.R. Kneller, Y. Qiu, P.L.W. Tregenna-Piggott, C.M. Brown, J.R.D. Copley, R.M. Dimeo, DAVE: A comprehensive software suite for the reduction, visualization, and analysis of low energy neutron spectroscopic data, Journal of Research of the National Institute of Standards and Technology 114(6) (2009) 341-358.

[37] J.J. Thomas, S.A. FitzGerald, D.A. Neumann, R.A. Livingston, State of Water in Hydrating Tricalcium Silicate and Portland Cement Pastes as Measured by Quasi-Elastic Neutron Scattering, Journal of the American Ceramic Society 84(8) (2001) 1811-1816.

[38] A.J. Allen, J.C. McLaughlin, D.A. Neumann, R.A. Livingston, In situ quasi-elastic scattering characterization of particle size effects on the hydration of tricalcium silicate, Journal of Materials Research 19(11) (2004) 3242-3254.

[39] C.A. Rees, J.L. Provis, G.C. Lukey, J.S.J. van Deventer, The mechanism of geopolymer gel formation investigated through seeded nucleation, Colloids and Surfaces A: Physicochemical and Engineering Aspects 318(1-3) (2008) 97-105.

[40] E.I. Diaz, E.N. Allouche, S. Eklund, Factors affecting the suitability of fly ash as source material for geopolymers, Fuel 89(5) (2010) 992-996.

[41] R.K. Iler, Effect of adsorbed alumina on the solubility of amorphous silica in water, Journal of Colloid and Interface Science 43(2) (1973) 399-408.

[42] S.A. Bernal, J.L. Provis, Durability of Alkali-Activated Materials: Progress and Perspectives, Journal of the American Ceramic Society 97(4) (2014) 997-1008.

[43] H.M. Jennings, A model for the microstructure of calcium silicate hydrate in cement paste, Cement and Concrete Research 30(1) (2000) 101-116.

[44] P.D. Tennis, H.M. Jennings, A model for two types of calcium silicate hydrate in the microstructure of Portland cement pastes, Cement and Concrete Research 30(6) (2000) 855-863.

[45] C.A. Rees, J.L. Provis, G.C. Lukey, J.S.J. van Deventer, In Situ ATR-FTIR Study of the Early Stages of Fly Ash Geopolymer Gel Formation, Langmuir 23(17) (2007) 9076-9082.

[46] C.A. Rees, J.L. Provis, G.C. Lukey, J.S.J. van Deventer, Attenuated Total Reflectance Fourier Transform Infrared Analysis of Fly Ash Geopolymer Gel Aging, Langmuir 23(15) (2007) 8170-8179. 